\title{
SEGURANÇA, RISCO E GUERRA NA CIDADE: UMA RELAÇÃO ENTRE URBANIZAÇÃO, TÉCNICAS DE MILITARIZAÇÃO E MECANISMOS DE POLICIAMENTO.
}

\author{
Tamires de Oliveira Garcia ${ }^{1}$ \\ Renata Almeida da Costa ${ }^{2}$
}

\section{RESUMO}

O presente artigo estabelece conexões entre segurança pública e urbanização, com o objetivo de demonstrar que as sensações de risco e de insegurança contemporâneas têm origem, também, no estilo de vida das cidades. Para tanto, é adotada a investigação bibliográfica como metodologia de pesquisa, ao passo que o marco teórico recai na sociologia de Giddens e de Bauman. Desse modo, o texto possui três partes fundamentais: a que analisa a terminologia "risco e medo na cidade"; a que reflete sobre a lógica da guerra na cidade; e a que apresenta a instituição policial no Brasil, a partir de suas raízes históricas.

Palavras-chave: segurança; risco; guerra; cidade; polícia.

\section{SECURITY, RISK AND WAR IN THE CITY: A RELATIONSHIP BETWEEN URBANIZATION, MILITARIZATION TECHNIQUES AND POLICING MECHANISMS.}

\begin{abstract}
This paper establish connections between public safety and urbanization with the aim of demonstrating that the contemporary sensations of risk and insecurity are originate of the urban lifestyle. For this purpose, bibliographical research is adopted as a research methodology, while the theoretical framework rests on the sociology of Giddens and Bauman. In this way, the text has three fundamental parts: the first one that analyzes the terminology "risk and fear in the city"; the second one that reflects on the logic of the war in the city; and the third one that presents the police institution in Brazil, from its historical roots.
\end{abstract}

Keywords: security; risk; war; city; police.

\section{INTRODUÇÃO}

\footnotetext{
${ }^{1}$ Mestranda do Programa de Pós-Graduação em Direito e Sociedade da Universidade La Salle - Bolsista CAPES. Bacharela em Ciências Jurídicas e Sociais pela Pontifícia Universidade Católica do Rio Grande do Sul (PUCRS). E-mail: og.tamires@ gmail.com.

${ }^{2}$ Doutora em Direito pela UNISINOS, Mestre em Ciências Criminais pela Pontifícia Universidade Católica do Rio Grande do Sul e graduada em Direito pela Universidade de Passo Fundo (1998). É professora e coordenadora do Curso de Mestrado em Direito e Sociedade da Universidade La Salle e professora do curso de Graduação em Direito. Tem experiência na área de Direito, com ênfase em Direito Penal e Criminologia, atuando principalmente nos seguintes temas: criminalidade organizada, controle social, sociedade, terrorismo, cultura do medo e urbanização. É integrante do Cadastro Nacional e Internacional de avaliadores do CONPEDI - Conselho Nacional de Pesquisa e Pós-Graduação em Direito. E-mail: renata.costa@unilasalle.edu.br.
} 
Esta investigação versa sobre a temática da segurança pública, a partir da observação das características da urbanização das grandes cidades e do emprego de técnicas de militarização em solo citadino. Com o afã de delinear os parâmetros entre esses temas, se faz necessário analisar o modo de organização da sociedade contemporânea e a relação disso com as instituições sociais, especificamente com os mecanismos de policiamento.

Isso se justifica porque, como assinala Anthony Giddens, a difusão das instituições na época atual é uma das agendas das Ciências Sociais, estando diretamente relacionada à possibilidade de universalização por meio dos processos de globalização. Ademais, o alastramento das organizações enquanto instituições está também vinculado aos processos de mudança intencional desses mesmos organismos. (GIDDENS, 1997)

A relação entre sociedade, Estado e Direito (Penal) aqui se faz necessária porque, desde uma percepção global, tem-se o reconhecimento de que os estilos de vida da sociedade ocidental contemporânea são afetados mutuamente. Nesse compasso, estratégias de controle social (tanto formal quanto informal) se comunicam por uma espécie de heteronormatividade que transparece incluir elementos comuns (como risco, certeza, incerteza, determinação, complexidade) às decisões na área da segurança.

Assim, pode-se dizer que é inegável que o impacto do processo de globalização se dê sobre a vida cotidiana e que tenha influência global, podendo pequenas decisões afetar a vida de pessoas do outro lado do mundo, implicar em deteriorações ecoló gicas profundas, produzindo resultados inesperados de inúmeras formas. Essas novas trocas do dia a dia produzem relações próximas entre agrupamentos, ou até mesmo reflexos em instituições como o Estado, que não deixa de existir, mas tende a se reorganizar. (GIDDENS, 1997)

Desse modo, uma investigação de cunho jurídico-social sobre o assunto da segurança urbana e do Direito (Penal), não pode ignorar a importância de se pensar as instituições do Estado, seu modo de atuação e a influência que exercem sob o aspecto, principalmente, da segurança.

Em consequência, o que se quer demonstrar depende das respostas aos seguintes questionamentos: (um) as características sociológicas do "medo" e do "risco" são percebidas na estrutura de gestão das grandes cidades; (dois) há uma lógica de guerra que se apresenta nas grandes cidades; (três) é a instituição policial o instrumento 
adotado pelo sistema jurídico penal para a mitigação dos sentimentos de medo e de insegurança urbanos?

Qualquer resposta a essas reflexões demanda uma contextualização sociológica que, neste trabalho, adota a "sociedade da informação" ou "sociedade do consumo" para uma definição epocal que se associa à ideia de encerramento de um período: pós modernidade, pós-modernismo, sociedade pós-industrial. Além disso, esse ponto de partida é relevante para a concentração do estudo em torno das transformações institucionais atuais, em que se afirma estar ocorrendo um deslocamento de um sistema de manufatura para outro mais centrado na informação. (GIDDENS, 1991)

Nesse cenário, observar como ocorrem as relações dentro das instituições do Estado é um trabalho necessário para compreender seu impacto na sociedade. São novas formas de organização e de troca que precisam ser compreendidos sob a lógica deste novo período, considerando que as modificações que têm ocorrido dentro de espaços que deveriam ser estruturados para oferecer a garantia de segurança e o exercício de direitos.

Pensando as transformações deste novo tempo a partir dos questionamentos suscitados por cientistas sociais, é que se pretende vencer possível desorientação sobre a obtenção de conhecimento sistemático sobre a organização social. Até porque, os indivíduos têm experimentado a sensação que os eventos da sociedade parecem fora do controle, sugerindo que "estamos alcançando um período em que as consequências da modernidade estão se tornando mais radicalizadas e universalizadas do que antes." (GIDDENS, 1991, p. 13).

São as novas relações entre os indivíduos e as instituições do Estado que guiam este estudo. Mais especificamente, as relações estabelecidas entre os riscos que pairam na cidade, o processo de urbanização e a forma de policiamento no Brasil que sugerem uma leitura fenomenológica crítica. Portanto, ao longo deste escrito, são apresentadas algumas perspectivas acerca de definições de segurança e de risco na sociedade atual, estabelecendo-se também uma relação com novos prismas de perigo e a lógica de guerra nas cidades, para ao final apontar o que constitui algumas raízes e dilemas atuais de polícia no país.

2 RISCO E MEDO NA CIDADE 
A modernidade e o que vem se desenvolvendo a partir desse período geraram fenômenos dicotômicos. As instituições sociais e sua ampla difusão global criaram oportunidades maiores para os indivíduos, ao passo em que se instituiu um cotidiano de fomento de sensação de insegurança, como que sempre à espreita de um risco inesperado.

Nesse contexto, temas como a divisão do trabalho, o individualismo moral e a expansão da burocracia se tornaram comuns às ciências sociais. Contudo, o debate sobre eles não foi suficiente para prever todos os fenômenos sociais que geram conflitos no século atual. Assim, o potencial destrutivo ao meio ambiente material e a nova organização de forças e armamentos militares não foram por eles antevistos, por exemplo. (GIDDENS, 1991)

Faz-se difícil compreender de que maneira a constante (re)organização da sociedade e das instituições que compõem o Estado influenciam as relações que atualmente desenvolvem. Para empreender um caminho neste dilema, é preciso levar em conta algumas das inúmeras modificações que ocorreram ao longo do tempo.

Pensar a segurança, a violência e os riscos na sociedade global implica reconstruir como se deu o processo de urbanização do século XXI. Stephen Graham destaca que, no início do séc. XX, 1 em cada 10 das 1,8 bilhões de pessoas viviam em cidades (o que já era considerado uma proporção sem precedentes, em que pese a maior parte da população continuasse sendo rural e agrícola). Fora uma época em que apenas uma pequena parte da população urbana (a maioria localizada nas metrópoles do norte global) participava da efervescência em torno de assuntos industriais, comerciais e governamentais de um mundo colonial cada vez mais conectado. (GRAHAM, 2016)

No decorrer do meio século seguinte (1950) a humanidade alcançou o número de 2,3 bilhões de pessoas. A população urbana quase triplicou, atingindo mais de 500 milhões de pessoas, mas ainda compondo menos de 30\% do total. Já entre 1957 e 2007 a população era de 6,7 bilhões de pessoas, sendo que metade podia ser considerada urbana. (GRAHAM, 2016)

É possível perceber que a jornada em direção ao século XXI foi de amplo crescimento populacional urbano. Desse processo, não é de se admirar que muitas relações tenham sido alteradas, sejam elas de cunho privado, manifestando-se no ambiente doméstico, ou também de caráter público, representadas por novas frentes que se colocavam no espaço urbano. 
Foi assim que se chamou de "século urbano" o século XXI, visto que parece não haver fim para a urbanização do mundo. Além disso, essa Era demonstra projeções de mais de 10 anos à frente, caso o aumento demográfico siga no mesmo ritmo. Segundo Graham, menciona-se que em pouco mais de 4 décadas o planeta acomodará 7 bilhões de habitantes humanos (4 bilhões a mais que em 2007) e que a maioria estará em cidades em desenvolvimento e megacidades da Ásia, África e da América Latina, ressaltando que nações desenvolvidas ainda estarão crescendo, mas timidamente se comparado à explosão urbana do sul global. (GRAHAM, 2016)

Nessa equação, faz-se necessário considerar que as localidades com previsão de maior crescimento urbano são também as que abrigam alguns dos países considerados mais violentos no mundo. Ou seja, em algum momento as relações estabelecidas entre os indivíduos se manifestarão nas cidades, espaços atualmente imersos em sentimentos de medo e desconfiança.

Por consequência, o processo de urbanização, tendo modificado as relações entre as pessoas, entre os indivíduos e o trabalho, também estabeleceu uma nova lógica nas cidades. Pautados nas novas relações sociais, os sentimentos difusos de medo e insegurança são produzidos e reproduzidos pela mídia e por outros sistemas e instituições sociais. Como consequência indissociável, tem se transformado em instrumento de controle sócioespacial. (GRAHAM, 2016)

Amparado por Robert Castel, Zygmunt Bauman indica que a sensação de insegurança moderna não se justifica pela perda de segurança, mas por uma "nebulosidade de seu objetivo". Com esse fundamento, explica esse fenômeno a partir do individualismo moderno, argumentando que as regras de proteção do nosso tempo não foram construídas de maneira sólida, o que permitiu a difusão da ideia de que o perigo está em toda parte. (BAUMAN, 2009, p. 9)

O autor apresenta um panorama acerca das transformações ocorridas nas relações de trabalho na era moderna, que revelou dois momentos: um vinculado à supervalorização do indivíduo, e outro, que veio logo depois do primeiro, marcado pela fragilidade e vulnerabilidade dos indivíduos, resultante da falta de proteção dos antigos vínculos que eram estabelecidos. Isso fez com que o estado moderno fosse obrigado a administrar o sentimento de medo, desenvolvendo novas redes de proteção. Foi preciso que se desenvolvesse uma espécie de solidariedade coletiva, exemplificadamente empresarial, sindical e profissional, o que permitiu criar relações de confiança e um 
refúgio seguro onde era possível a disputa, mas, ao mesmo tempo, uma estabilidade entre os grupos de trabalho, também mantendo os riscos do mercado de trabalho distantes. (BAUMAN, 2009)

Em consequência desse pensamento, suscita-se que foi a redução do controle estatal que deu início aos medos modernos. As relações anteriormente demonstradas incorporam o que o autor chama de modernidade sólida, onde se desenvolveu uma espécie de solidariedade que administrava o medo. A partir do momento que as proteções estatais foram desmanteladas, também essa solidariedade se dissolve. Para Bauman, (2009, p. 19)

O medo do desconhecido - no qual, mesmo que subliminarmente, estamos envolvidos - busca desesperadamente algum tipo de alívio. As ânsias acumuladas tendem a se descarregar sobre aquela categoria de "forasteiros" escolhida para encarnar a "estrangeiridade", a não-familiaridade, a opacidade do ambiente em que se vive e a indeterminação dos perigos e das ameaças. [...]O estrangeiro é, por definição, alguém cuja ação é guiada por intenções que, no máximo, se pode tentar adivinhar, mas que ninguém jamais conhecerá com certeza.

A esse fenômeno, Bauman atribui o fortalecimento de uma exclusão social irrevogável, de pessoas consideradas supérfluas de modo permanente. A partir dessa reflexão desenvolve uma analogia entre pessoas sem trabalho e criminosos, considerando que em ambos os grupos as pessoas são vistas como aquelas que não podem mais ser "reeducadas" e "restituídas à comunidade". Assim se estrutura, na cidade, uma polarização entre o que o autor chama de "primeira fila" e "última fila": sendo os primeiros aqueles que podem escolher o local para morar, preferindo o resguardo de simplesmente serem deixados em paz para direcionar seu olhar a questões globais, enquanto os outros estão condenados a permanecer no mesmo local e devem contentar-se com as questões locais. (BAUMAN, 2009)

Tratam-se, aqui, de reflexões de cunho excludente e que reverberam nos mais diferentes espaços da sociedade. Nessa análise, o contexto brasileiro se revela imerso em constantes demonstrações de desigualdades e dificuldades de enfrentamento de caráter social.

Pensando ainda a sociedade contemporânea - ou, como toma o autor, a modernidade reflexiva -, Ulrich Beck propõe uma outra forma de ver a difusão os riscos. Para ele, a distribuição dos riscos não corresponde às diferenças sociais, econômicas e geográficas da primeira modernidade, sugerindo que a sociedade do risco atinge nações e classes sociais sem respeitar fronteiras de nenhum tipo. (BECK, 2011) 
Beck propõe que a reflexividade é um componente estrutural da sociedade, em um mundo globalizado que o elemento constituinte é a incerteza. Para ele, o risco é ubíquo, assumindo dimensões e proporções globais. (BECK, 2011)

Considerando diferentes posicionamentos, manifestados em diferentes momentos, denota-se um caráter de transitoriedade a respeito da ideia de risco na sociedade. Compreende-se que se instaurou um ambiente social marcado pelo medo, esse sentimento que não pode ser calculado, e que é difundido por meio do risco, instituto que as corporações de segurança esforçam-se em criar mecanismos para controlar.

Diversas são as formas de perceber o risco e a expressão do medo na sociedade contemporânea. Delas, destacam-se estudos sociais que demonstram que a produção do conhecimento sobre o território e suas dinâmicas demandam o exame de fatores de afetação da sociedade e do próprio Direito.

Nisso, tem-se, também, a emergência dos estados penais que possuem "uma imagem simbólica que pode ser percebida pela organização social dos espaços urbanos". Conforme Costa e Guia (2017):

\footnotetext{
Pensada a partir de uma "Sociologia dos muros", a paisagem visual do medo, caracterizada tanto pelas fachadas dos empreendimentos urbanos comercializados na contemporaneidade quanto pela criação e manutenção pública de edifícios e terrenos de custódia de pessoas, escancara o perfil de uma sociedade que regula a diversidade e procura oferecer segurança mediante práticas seletivas e estigmatizantes de indivíduos e de locais de moradia.
}

Diante dos cenários dos grandes centros urbanos, caracterizados pelo fechamento dos espaços públicos, da fortificação de condomínios horizontais e verticais, e da implementação de artefatos de vigilância pessoal e tecnológica, verificase a implantação de técnicas de militarização nas cidades.

\section{A LÓGICA DA GUERRA NA CIDADE}

Enfrentando questões que envolvem a complexidade da sociedade contemporânea, Graham trata da colonização de novas técnicas de segurança que estão sendo estabelecidas pelo globo. São mecanismos pensados a partir de lógicas militarizadas de controle, rastreamento, triagem e outros procedimentos que podem permitir o acesso a informações antes sequer imaginadas. (GRAHAM, 2016) 
Apreende-se que há características que estão sendo incorporadas não mais a eventos específicos, mas (também) ao cotidiano da população. Sob o argumento de uma suposta proteção, mecanismos de controle estão sendo instituídos às corporações de segurança, em atividades que apontam claros inimigos a serem atingidos. Evidenciando isso, pode-se perceber que:

\begin{abstract}
Além da comercialização da segurança, o comércio crescente de espaços cada vez mais fechados provoca um distanciamento das características originais da própria cidade. E isso, por seu turno, resulta em uma desconexão do espaço público do restante da população que, paradoxalmente, parece ter aumentada, cada vez mais, a percepção do perigo. (COSTA e GUIA, 2017)
\end{abstract}

Sob esse enfoque, as técnicas de controle social debruçam estratégias sobre a personificação do ator dos perigos, considerados, assim, "inimigos" sociais. A eles se destinam as técnicas de militarização. Em que que pese Graham (2016) pensar o desenvolvimento de técnicas de militarização a partir dos contextos de guerra que dispõem terroristas em diversas partes do mundo, há, também, métodos que procuram combater essas forças locais com tecnologias de origem privada cada vez mais aprimoradas.

Tal conjuntura, que para fins deste trabalho, tanto pode ser internacional quanto nacional, forma a guerra assimétrica, quando forças se organizam a partir de informações extraídas da internet, YouTube, tecnologia de GPS, celulares, controle de imigração, serviços de comunicação em geral para desafiar a inteligência dos Estadonação.

Por conseguinte, observa-se que a ideia de militarização da vida urbana é um processo complexo, que perpassa a naturalização da demonização dirigida a certos inimigos e aos locais inimigos, contando com uma

[...] normalização dos paradigmas militares de pensamento, ação e política; esforços de disciplinar agressivamente corpos, espaços e identidades considerados não condizentes com noções masculinizadas (e interconectadas) de nação, cidadania ou corpo; e o uso de uma ampla e diversificada propaganda política que romantiza ou higieniza a violência como um meio de vingança legítima ou de conquista de algum propósito divino. (GRAHAM, 2016, p. 122)

Percebe-se, portanto, a difusão cada vez mais legitimada do exercício de um poder que se estrutura a partir do processo de identificação de um padrão (o masculino) e de uma hierarquia. Mais do que operar em investigações de casos específicos, as corporações têm encontrado amparo para empreender arbítrios de forma discricionária e abusiva. 
Graham (2016) aponta a existência de novas relações entre nações, soldados e cidadãos, que consequentemente estão se refletindo na urbanização contemporânea. Um desses fenômenos, que está gerando um senso coletivo que alimenta um discurso de que as cidades precisam estar "na mira" e ser "pacificadas" pelo poder militar, é a atual importância das áreas rurais para o militarismo e patriotismo, que se baseia na política conservadora dessas zonas - muitas vezes ligada à ideia de ódio ou suspeita de supostos horrores ou ameaças de impurezas raciais e outros fatores considerados de risco nas cidades.

Outro aspecto a ser considerado é o uso cada vez maior de tecnologias de controle, monitoramento, comunicação, simulação e mira, mecanismos "cujo objetivo original era o uso militar [e] se tornaram fundamentais para praticamente todos os atos da vida e do consumo urbanos em cidades industriais desenvolvidas" (GRAHAM, 2016, p. 124). São sistemas de controle eletrônico que se tornaram as novas arquiteturas estratégicas da vida citadina, que atualmente estão dispostos por toda a sociedade, naturalizando-se que o cotidiano esteja em constante vigilância.

Cuida-se aqui de um fenômeno absolutamente preocupante se pensada a vida nas grandes metrópoles, locais que comumente recebem as mais diferentes formas de manifestação (política, econômica, cultural). Quando se percebe que o alastramento do uso de mecanismos de controle é cada vez maior, deve-se questionar em que aspectos essas medidas estão se refletindo no exercício de direitos que deve ser assegurado à população, bem como ao resguardo de ambientes seguros para isso.

Os dispositivos análogos à guerra, nas cidades, além de onipresentes, são também consumidos como verdadeiros espetáculos visuais e discursivos na mídia. É uma divulgação que retroalimenta a noção de que estes instrumentos são permanentemente necessários para a manutenção da segurança pública. Trata-se de uma relação de divulgação que além de gerar entretenimento com cenas de violências e erotizar armamentos de alta tecnologia também torna a morte curiosamente invisível. (GRAHAM, 2016, p. 133)

Assim se revela uma das sombrias facetas das novas relações estabelecidas na sociedade da informação. Os aparatos utilizados para controlar a vida e o cotidiano nas cidades não só se amplifica, como também atinge de forma generalizada e também manipulada os estratos sociais - na maior parte das vezes orquestrando cenas que geram 
um sistema que reproduz a lógica do medo e, por consequência, a necessidade da difusão dos mecanismos de controle.

Diante dessas tendências, o resultado é que o desenho urbano cada vez mais reflete práticas de "segurança" que misturam aparatos comerciais, militares e de segurança com culturas temerosas de consumo, cidadania e mobilidade civil:

\begin{abstract}
[...] enquanto espaços e sistemas cotidianos da vida urbana são colonizados por tecnologias de controle militar, e enquanto conceitos de guerra e policiamento, doméstico e internacional, paz e guerra se tornam menos distintos, surge uma grande onda em um complexo industrial convergente que engloba segurança, monitoramento, tecnologia militar, prisões, instrumentos de punição e entretenimento eletrônico. Dentro do aparato mais amplo da rede de entretenimento mídia-militar-industrial, a fusão dessas indústrias explora a fertilização cruzada e a diluição entre os imperativos militares tradicionais da guerra, externos ao Estado, e os imperativos do policiamento interno. (GRAHAM, 2016, p. 137)
\end{abstract}

Para Teresa Caldeira (2000), esse contexto se reflete como uma forma de exclusão social nas cidades, gerando padrões de segregação de indicadores geográficos, demográficos e socioeconômicos. A autora aponta que em São Paulo (assim como em muitas cidades do mundo) desenvolveu-se um novo padrão de urbanização - no Brasil, desde os anos 40 -, chamado de centro-periferia. Esse desenho delineou um espaço disperso ao invés de concentrado, contando com as classes sociais vivendo longe umas das outras: classes média e alta em bairros centrais, pobres na periferia. Ainda, a aquisição de casa própria se tornou regra, para ricos e pobres, e o sistema de transporte dividiu-se no uso de ônibus para a classe trabalhadora e automóveis para as classes média e alta.

Na década de 70, São Paulo tinha se tornado uma cidade na qual as pessoas de diferentes classes sociais não só estavam separadas por grandes distâncias, mas também tinham tipos de habitação e qualidade de vida urbana radicalmente diferentes. [...] Em resumo, nos anos 70 os pobres viviam na periferia, em bairros precários e em casas autoconstruídas; as classes média e alta viviam em bairros bem equipados e centrais, uma porção significativa delas em prédios de apartamentos. O sonho da elite da República Velha fora realizado: a maioria era proprietária de casa própria e os pobres estavam fora do seu caminho. (CALDEIRA, 2000, p. 227-228)

Esse conjunto de fatores integra o que Débora Pastana trata como a cultura do medo instaurada na sociedade atual. Segundo ela, trata-se de uma somatória de valores que estão associados à criminalidade e percepções do senso comum que reproduzem uma estrutura hegemônica de insegurança, perpetuando uma forma de dominação de poder marcada pelo autoritarismo e rejeição ao exercício de princípios democráticos. (PASTANA, 2005) 
Concordando com as ideias propostas pelas autoras, tem-se que o cenário brasileiro é marcadamente excludente, tendo inclusive o espaço urbano estruturado a partir dessa lógica. Considerando, portanto, o contexto de uma sociedade desigual, em que a influência da cultura do medo se manifesta cada vez mais, é preciso compreender a ingerência dos mecanismos de controle nas corporações de segurança do país.

\section{INSTITUIÇÃO POLICIAL NO BRASIL: RAÍZES HISTÓRICAS E PERSPECTIVAS ATUAIS}

A previsão da segurança pública como dever do Estado e responsabilidade de todos consta do artigo 144 da Constituição Federal. Conforme previsto no diploma legal, ela deve ser exercida para a preservação da ordem pública e defesa das pessoas e do patrimônio, contando com os órgãos da i) polícia federal; ii) polícia rodoviária federal; iii) polícia ferroviária federal; iv) polícias civis; e v) polícias militares e corpos de bombeiros militares.

A primeira vez que o termo "segurança pública" foi utilizado foi na Constituição de 1937. Antes disso, já se tinha o uso do termo "segurança interna", que era aquilo que dizia respeito ao controle da ordem. A partir dessa determinação, caberia à União garantir "o bem-estar, a ordem, a tranquilidade e a segurança públicas". Sendo que no ano anterior foi promulgada a Lei n. 192, vinculando as atividades policiais militares aos estados, deixando à União somente um papel de fiscalização de controle, por meio do exército. Considerando essa lei, as polícias militares eram responsáveis pela segurança interna, enquanto em 1937 a Constituição falava em segurança pública. Por isso o conceito de segurança pública não conseguiu se institucionalizar, já que não teve força para mudar a atuação das polícias estaduais. (LIMA; COSTA, 2014)

O período ditatorial, que compreendeu 1964-1985, reforçou a ideia de segurança interna, através de constituição de 1967, que previa como competência da Polícia Militar a "manutenção da ordem e segurança interna nos estados, territórios e no distrito federal". O mesmo período também foi marcado pela ideologia de "segurança nacional", reivindicada pelas forças armadas, que tinha como objetivo principal identificar e eliminar os "inimigos internos", ou seja, todos aqueles que questionavam e criticavam o regime estabelecido. (LIMA; COSTA, 2014) 
O período anterior à constituinte de 1988 foi fortemente marcado pela submissão a regimes autoritários e repressivos. Com frequência argumenta-se que as influências deixadas pelos períodos colonial e ditatorial contaminaram as instituições encarregadas de garantir a segurança pública e de investigar delitos no país, afirmandose que a transição democrática pela qual passa o Brasil não gerou mudanças significativas na cultura repressiva:

Em consequência, embora o Brasil tenha iniciado seu processo de
democratização há mais de vinte anos, as instituições policiais ainda
permaneceriam com muitos vícios e hábitos do período ditatorial. A
característica mais marcante desse processo consiste na prática policial
violenta e autoritária, que reflete em seus métodos de investigação e
abordagem. (GONÇALVES, 2014, p. 109)

Dessa maneira é que Paulo Sérgio Pinheiro e Emir Sader explicam que a atuação policial no país nunca foi voltada à proteção dos cidadãos, de forma que a segurança fosse melhor concretizada. Os governos exercidos por militares compreendidos pelo Estado Novo, entre 1935 e 1945, e pelo golpe civil-militar que se estendeu entre 1964 e 1985 - foram marcados por uma profunda opressão e violência por parte do Estado. Segundos os autores, "a atuação policial no Brasil sempre se exerceu prioritariamente contra as classes populares, contra a maioria dos cidadãos". (PINHEIRO; SADER, 1985, p. 79)

Em que pese a constante atuação violenta da polícia, a percepção popular só registra a repressão nos regimes de exceção, quando ela fica mais evidente. Durante o Estado Novo, por exemplo, essa atuação foi mascarada por realizações econômicas, nacionalistas e sociais (PINHEIRO; SADER, 1985). Assim, por mais arbitrárias que sejam as medidas tomadas pelas instituições de segurança, quando empreendidas e divulgadas supostas conquistas governamentais as medidas abusivas são facilmente camufladas.

É pensando a realidade latino-americana que se tem como fundamental a análise criminológica acerca do exercício arbitrário do poder. Nesse cenário, países que antes foram colônia, mesmo depois da independência, precisaram manter políticas econômicas monetaristas e de dependência que levaram à criação do sistema de controle social conhecido por doutrina da segurança nacional (GONÇALVES, 2014). A segurança nacional foi compreendida pela reivindicação das forças armadas que tinha como objetivo principal identificar e eliminar os "inimigos internos", ou seja, todos aqueles que questionavam e criticavam o regime estabelecido (LIMA; COSTA, 2014). 
Durante um longo período, portanto, o Brasil viveu momentos em que foi difundida a ideia de perseguição a um inimigo comum, discricionariamente estabelecido pela ordem. Nesse contexto, é preciso levar em consideração a literatura que indica que a polícia brasileira opera com resquícios ditatoriais e arbitrários, ainda agindo de forma excludente e seletiva.

Dito isto, tem-se que seria necessário um conceito para compreender a dimensão da identidade, limites e requisitos da atuação policial. Vasta é a literatura que procura compreender o policiamento e explicá-lo por meio de teorias que perpassam desde o tradicional dilema da lei e da ordem, como também associando o exercício das funções como forma de regulação, controle social e dominação de classes - essas últimas ligadas ao uso da força. (MUNIZ; PROENÇA JR., 2014)

Não há se tirar um consenso deste amplo debate teórico, mas pode-se dizer que são trabalhos que dialogam, de uma maneira ou de outra, com o que é proposto por Egon Bittner, que propõe o cerne da conceituação por meio da ideia de mandato policial. Para ele, somente a polícia está equipada e autorizada para lidar com as exigências de força que podem dela ser solicitadas:

A polícia é equipada tanto em termos de equipamento quanto de preparo para o exercício de seu mandato. É autorizada porque lhe são conferidos respaldo legal e consentimento social para policiar. E responde por qualquer exigência, qualquer situação de perturbação de um determinado status quo que corresponde, em termos amplos, à paz social. (MUNIZ; PROENÇA JR., 2014, p. 493)

Esse conceito pretende superar a dicotomia existente entre oficial da lei e oficial da ordem, não reduzindo a instituição às práticas de policiamento. Nessa linha, a ideia não é pensar o que as polícias fazem ou por que fazem, mas compreender o que a polícia é. Dessa forma, seria possível estabelecer uma dimensão entre o que se espera que a polícia faça - por meio da formulação do que constitui o espírito da instituição - e o que ela de fato faz. (MUNIZ; PROENÇA JR., 2014)

A partir desta perspectiva pode-se problematizar "por que é a polícia que é chamada quando a força pode ser útil? O que distingue o uso de força pela polícia do uso de força por quaisquer outros atores?” A resposta vem no sentido de pensar a instituição como um órgão que se espera que se interponha entre interesses em conflito que estejam afetando a paz social, direitos e garantias ou as leis. Dessa forma, compreende-se que a polícia deve produzir alternativas de obediência com 
consentimento social e que estão sob controle coletivo - que estão sujeitos à apreciação política, social ou judicial a posteriori ${ }^{3}$. (MUNIZ; PROENÇA JR., 2014, p. 494)

Não se pode deixar de considerar, ainda, que a natureza da ação policial tem limites - seja para a aplicação, seja para o alcance que pode encontrar para os conflitos. Essa característica determina um caráter finito e provisório para a solução policial, compreendendo-se que a coerção pela força possui tempo determinado, inviabilizando a extensão de sua sustentação e definindo a impossibilidade do uso da força dar conta das causas dos eventos sociais em que a polícia intervém.

É preciso ponderar que o tema escolhido é composto por uma multiplicidade de agências, práticas e discursos diferentes, caracterizando-se, não raras vezes, por políticas e ações contraditórias entre si. Assim como descreveu David Garland (2008, p. 366), "esta não é uma época em que as velhas instituições e práticas estão sendo abandonadas em benefício de novas que estão sendo criadas".

A época atual se estrutura a partir de um entrelaçamento entre o passado e o reflexo dele na sociedade. O campo penal, o controle do crime e a justiça criminal se organizam em torno de políticas e sensibilidades culturais, que acabam por guiar as práticas das instituições envolvidas nessas relações. Pode-se dizer, inclusive, que a arquitetura institucional da modernidade penal não foi alterada, tendo como modificações apenas a distribuição e funcionamento do aparato estatal. (GARLAND, 2008)

O policiamento, por exemplo,

[...] ficou mais "esperto", mais centrado, mais ligado às circunstâncias locais, mais sensível à pressão pública, mais disposto a trabalhar com a comunidade e a enfatizar a prevenção. [...] A polícia iniciou seu ingresso na fase pósburocrática da instituição, começando a desenvolver vínculos flexíveis com outros parceiros na tentativa de somar forças em lugar de monopolizar os esforços. Outrossim, os objetivos declarados da polícia mudaram, às vezes de forma acentuada, e novas táticas paulatinamente definem como são utilizados seus recursos. Todavia, estudos sobre orçamento e rotinas de trabalho da polícia sugerem que as práticas diárias da maior parte das forças policiais não se alteraram tanto assim. (GARLAND, 2008, p. 367-368)

\footnotetext{
${ }^{3}$ Isso porque compreende-se que "a decisão sobre a forma de agir pertence ao policial individual, que depende do seu poder discricionário para poder realizar o seu trabalho.” Dessa forma, a práxis policial está ligada a uma abordagem autônoma e discricionária, dando-se no tempo presente da vida social, inscrevendo-se "numa sucessão de eventos, conexos ou desconexos, contínuos ou descontínuos, envolvendo dinâmicas multi-interativas, cujas intensidade, densidade e consequência impõem a tempestividade do agir para o agente policial e a provisoriedade de suas soluções." (MUNIZ; PROENÇA JR., 2014, p. 496)
} 
A partir disso, tem-se que é possível perceber modificações na forma de agir policial. Em que pese a incompleta transição democrática do contexto brasileiro, em que se percebe a permanência de práticas autoritárias e excludentes, a literatura reconhece que a era atual permite o desenvolvimento de novos mecanismos e de uma abertura para também novos padrões de ação da polícia.

Não se pode esquecer que este enredo também é guiado pela forte sensação de medo que se instalou na sociedade. Como asseveram Costa e Wendt, poder-se-ia afirmar que a fragmentação dos conhecimentos, em especial o tecnológico e sobre a Internet, faz com que no seu paradoxo, não conhecimento, surjam sentimentos/sensações de insegurança, proliferando-se o medo (COSTA e WENDT, 2014). Neste ponto pode-se dizer que são sintomas de que o risco está presente em toda parte e que é constantemente reproduzido pela tecnologia da informação, fazendo com que o seu alastramento seja cada vez mais extenso e possibilitando a abertura para uma indústria da divulgação e apropriação dos supostos meios de combate à violência.

\section{CONSIDERAÇÕES FINAIS}

O presente escrito não tem por objetivo colocar fim a um debate complexo, que envolve tantos aparatos, mas sim problematizar as relações já enquadradas como reflexo da modernidade tardia com outras características do mesmo período.

Contudo, a pesquisa permitiu responder assertivamente aos questionamentos postos na introdução deste texto. Isto é, (um) é no território urbano que aas características sociológicas do "medo" e do "risco" são percebidas. Afinal, na estrutura de gestão das grandes cidades tem-se dois fenômenos interligados: o fechamento dos espaços (tanto públicos quanto privados) de convívio social e o emprego de artefatos de segurança (privados ou públicos).

A utilização de instrumentos de vigilância (câmeras, porteiros, seguranças privados) e o emprego de artefatos que promovem exclusão (muros, restrições de passagem, cercas, portões) e/ou o medo em si (uso de armas de fogo) perpetua a lógica da guerra. Assim, evidencia-se que há, nos espaços civis urbanos, práticas de militarização. Ou seja, respondido também o (dois) segundo questionamento ab initio formulado. 
Por fim, (três) com a análise histórica do surgimento e do desenvolvimento das polícias, verificou-se que a instituição policial - da forma tradicional como se apresenta - tem sido, nesses tempos de insegurança e de medo, o instrumento adotado pelo sistema jurídico penal para a representação do combate à insegurança pública. $\mathrm{O}$ apoio normativo e social à atuação vigilante das polícias é fator indissociável de uma cultura de controle social baseada na exclusão e no medo.

Contudo, não se logrou verificar que há no cerne das instituições estatais de controle social, um pensamento crítico organizado tendente a reconhecer que a paisagem visual do medo é algo que bem representa o estilo de vida das populações metropolitanas. Ao passo que, sem tal problematização, as políticas de segurança pública, seguirão operando simbólica e ineficazmente, enquanto instrumentos legislativos como o Direito Penal, permanecerão reproduzindo a lógica binária da inclusão e da exclusão social.

\section{REFERÊNCIAS BIBLIOGRÁFICAS}

BAUMAN, Zygmunt. Confiança e medo na cidade. Rio de Janeiro: Jorge Zahar Ed., 2009.

BECK, Ulrich. Sociedade de risco: rumo a uma outra modernidade. 2. ed. São Paulo: Ed. 34, 2011.

CALDEIRA, Teresa Pires do Rio. Cidade de muros: crime, segregação e cidadania em São Paulo. São Paulo: Ed. 34/Edusp, 2000.

COSTA, Renata Almeida da. GUIA, Maria João. A crimigração, a gestão do poder e a cultura do medo: do global aos espaços urbanos. In: BASSO, Ana Paula. MONTEIRO, Fernando Eduardo Batista Conde. SANTOS, Margarida Maria de Oliveira (orgs.)

Criminologias e política criminal. Florianópolis, CONPEDI, 2017, p. 29-46.

COSTA, Renata Almeida. Cultura do medo e espaço urbano: um olhar reflexivo sobre a sensação social de insegurança. In: Albert Noguera Fernández; Germano Schwartz. (Org.). Cultura e identidade em tempo de transformações: reflexões a partir da teoria do Direito e da Sociologia. 1 ed. Curitiba: Juruá, 2011, v. 1, p. 219-239.

COSTA, Renata Almeida da. NETO, Felix Araujo. Criminologias e política criminal II. Florianópolis: CONPEDI, 2016.

COSTA, Renata Almeida da. WENDT, Emerson. A internet e a fragmentação do Direito Penal no regforço da cultura do medo no Brasil: análise da adequação do Direito Penal para solucionar a conflituosidade digital. In: ANAIS da X Semana Científica Unilasalle. Canoas: Unilasalle, 2014. 
GARLAND, David. A cultura do controle: crime e ordem social na sociedade contemporânea. Rio de Janeiro: Revan, 2008.

GIDDENS, Anthony. A vida em uma sociedade pós-tradicional. BECK, Ulrich (org.). Modernização reflexiva: política, tradição e estética na ordem social moderna. São Paulo: Editora da Universidade Estadual Paulista, 1997.

As consequências da modernidade. São Paulo: Editora Unesp, 1991.

GONÇALVES, Vanessa Chiari. Tortura e cultura policial no Brasil contemporâneo. Rio de Janeiro: Lumen Juris, 2014.

GRAHAM, Stephen. Cidades sitiadas: o novo urbanismo militar. 1. ed. São Paulo: Boitempo, 2016.

LIMA, Renato Sérgio de; COSTA, Arthur Trindade. Segurança Pública. LIMA, Renato Sérgio de; RATTON, José Luiz; AZEVEDO, Rodrigo Ghiringhelli de (orgs.). Crime, polícia e justiça no Brasil. São Paulo: Contexto, 2014.

MENDES, José Manuel. Sociologia do risco: uma breve introdução e algumas lições. Coimbra: Imprensa da Universidade de Coimbra, 2015.

MUNIZ, Jacqueline; PROENÇA JR., Domício; Mandato Policial. LIMA, Renato Sérgio de; RATTON, José Luiz; AZEVEDO, Rodrigo Ghiringhelli de (orgs.). Crime, polícia e justiça no Brasil. São Paulo: Contexto, 2014.

PASTANA, Débora Regina. Cultura do medo e democracia: um paradoxo brasileiro. Revista Medições, Londrina, v. 10, n. 2, jul./dez., p. 183-198, 2005.

PINHEIRO, Paulo Sérgio; SADER, Emir. O controle da polícia no processo de transição democrática no Brasil. Temas IMESC, São Paulo, 1985. p. 77-95. 